\title{
Uma reflexão histórica acerca de rastros discursivos deixados pelo enunciado "Análise"
}

\section{Resumo}

Este artigo foi composto com o objetivo de tecer reflexões acerca de uma história da problematização daquilo que conhecemos por rigor, que se relaciona com disciplinas de Análise em cursos de licenciatura em matemática, tendo como principal motivação as divergências encontradas entre o que se espera daquela disciplina e o que, de fato, ocorre em salas de aula dos referidos cursos. Assim, utilizando um recorte de nossa dissertação de mestrado, seguimos rastros discursivos em que o enunciado "Análise" aparece em relação com outros enunciados e/ou discursos. Fizemos isso operando em aliança com o pensamento de Michel Foucault, mais especificamente aquele atrelado ao que ele denominou por Arqueologia, na tentativa de oferecer alguma resposta ao seguinte questionamento: o que pode uma disciplina de Análise? Nossos resultados proporcionam possibilidades de escape aos discursos comumente disseminados no interior da disciplina em comento, de maneira que encontramos pelo menos seis séries discursivas, nas quais o enunciado "Análise" estabelece alguma relação: relações com práticas de decomposição; relações com práticas de Geometria: análise e síntese; relações com práticas metodológicas de Cálculo Diferencial e Integral; relações com práticas limitantes infinitas e relações com práticas estruturantes de um corpo ordenado completo. Ao final, há uma breve reflexão acerca dos resultados encontrados, de modo que deixamos aberta ao o leitor a possibilidade de seguir suas próprias pistas e compor seu próprio caminho discursivo no emaranhado em que se encontra a disciplina de Análise.

Palavras-chave: Disciplina de Análise. História da Matemática. Arqueologia Foucaultiana. Práticas discursivas. 


\section{A historical reflection about discursive trails left by the utterance "Analysis"}

Danilo Olímpio Gomes

\section{Abstract}

This paper was composed with the purpose of reflecting on a history of the problematization about that we know by rigor that relates to disciplines of Analysis in undergraduate courses in mathematics, having as main motivation the divergences found between what is expected of that discipline and which, in fact, occurs in classrooms of said courses. Thus, using a cut from our master's dissertation, we follow discursive traces in which the statement "Analysis" appears in relation to other utterances and/or discourses. We did this by operating in alliance with the thought of Michel Foucault, more specifically that linked to what he called Archeology, in an attempt to offer some answer to the following question: what can an discipline of Analysis? Our results provide possibilities for escape to the discourses commonly disseminated within the discipline in question, so that we find at least six discursive series, in which the statement "Analysis" establishes some relation: relations with decomposition practices, relations with Geometry practices: analysis and synthesis, relations with methodological practices of Differential and Integral Calculus, relations with infinite limiting practices and relations with structuring practices of a complete ordered field. In the end, there is a brief reflection about the results, so that we leave open to the reader the possibility of following his/her own clues and compose his/her own discursive path in the entanglement in which is the discipline of Analysis.

Keywords: Discipline of Analysis. History of Mathematics. Foucault's Archeology. Discursive Practices. 


\title{
Introdução
}

Este artigo foi composto junto com um recorte de nossa dissertação de mestrado, defendida em 2013, sob o título "A disciplina de Análise segundo licenciandos e professores de matemática da educação básica" (GOMES, 2013), e o que estamos desenvolvendo em nossa tese de doutorado, a qual tenta vislumbrar compreensões acerca da problematização envolvendo o que é denominado por rigor na/da disciplina de Análise em cursos de licenciatura em matemática e adjacências.

Naquele tempo, estávamos interessados em tecer compreensões acerca das relações entre a disciplina em questão e os sujeitos que com ela mantêm algum contato, de modo a levar luz para algo que, assim como constatado por muitos autores como, por exemplo, Moreira; Cury; Vianna (2005), Moreira; Vianna (2016), Silva (2015), Otero-Garcia (2011), Martines (2012), Soares; Ferreira; Moreira (1999), dentre outros, encarávamos (e ainda encaramos) como um possível paradoxo: enquanto coordenadores de cursos de licenciatura, professores que lecionam Análise, educadores matemáticos, matemáticos, objetivos que constam em ementas da referida disciplina e mesmo alguns alunos afirmam categoricamente que aquela disciplina é julgada como fundamental para uma sólida formação de um futuro professor de matemática a atuar na educação básica, para uma parcela também significativa de sujeitos, notadamente naqueles que já estão prestes a atuar e/ou estão atuando nesse nível de ensino, a disciplina pode ser considerada como desnecessária para sua formação. É o que apontam, por exemplo, as falas de uma aluna da licenciatura e de uma professora da educação básica, em entrevistas para nossa pesquisa de mestrado:

\begin{abstract}
A Análise serviu para que? Somente para eu tirar meu diploma? Acredito que não; sei que tem alguma coisa lá, ainda mais porque teve muita gente que disse - e eu tenho consciência disso - que muitos dos seus conteúdos são necessários para eu poder explicar algumas coisas da educação básica. Só que, por eu não ter visto essas relações na graduação, pelo professor não as ter estabelecido, eu não sei o que tem de relação entre a educação básica e a disciplina de Análise, por exemplo. Desta forma, vou acabar sendo mecânica no ensino de muitos assuntos, porque não sei explicar muitas coisas, mesmo tendo visto esses assuntos na graduação (GOMES, 2013, p. 245).
\end{abstract}

Pode excluir, pode excluir a Análise do conteúdo da licenciatura (GOMES, 2013, p.164).

Assim, nos parece claro que, para a aluna da licenciatura, a disciplina é fundamental; no entanto, para ela, parece haver uma lacuna entre esse aspecto e a efetiva atuação do professor de matemática numa sala de aula da educação básica. Já para a professora, tudo se resolveria de forma mais drástica: a disciplina poderia ser retirada das ementas das licenciaturas. 
Neste caminho, imbuídos por uma crescente angústia, nos colocamos a pensar: o que habita um possível entre aquilo que a disciplina deveria promover e o que ela, de fato, promove para alunos da licenciatura e professores da educação básica, os quais podem ser vistos como uma das extremidades da formação de um professor de matemática? O que tínhamos em mãos naquele momento eram afirmações bilaterais, separadas por uma dualidade afirmada numa lógica de terceiro excluído: ou era uma disciplina necessária ou não era. Ocorre que, como dissemos, passou a nos interessar uma espécie de entre essas duas possibilidades lógicas, de maneira que percebemos que o foco de nossas indagações não deveria ser ludibriado por uma visão dual, mas, sim, que deveríamos operar numa espécie de linha limítrofe entre o verdadeiro e o falso, na tentativa de compor descrições que pudessem mostrar nuances, as quais somente uma ruptura causada na superfície daqueles (e de outros) discursos poderia fazer aparecer.

Em outras palavras, somente no momento em que nos dedicássemos a um estudo mais profundo acerca do que é compreendido por Disciplina de Análise - ou melhor, acerca do que pode uma disciplina de Análise - é que poderíamos operar escapes e vislumbrar linhas de fuga para essa aparente transparência discursiva (FOUCAULT, 2016), a qual teima em deixar a Análise acorrentada a um dos pratos da balança do certo e do errado, do útil e do não útil, do necessário e do não necessário, do ser e do não ser.

\section{Procedimentos metodológicos}

Lançar esforços na tentativa de responder à questão “o que pode?” não visa a uma definição acerca daquilo que se estuda (neste caso seria mais pertinente perguntar “o que é?”). Perguntar "o que pode?" interessa àquele que está preocupado com o acontecimento do que se questiona, com sua potência e/ou efetuação, com o seu funcionamento - tal como uma criança que desmonta seu carrinho de controle remoto e tenta compreender como todas aquelas peças podem fazer com que o carrinho se movimente.

Gostaria de fazer aparecer o que está próximo demais do nosso olhar para que possamos ver, o que está aí bem perto de nós, mas que nosso olhar atravessa para ver outra coisa. Devolver densidade a essa atmosfera que, à nossa volta, por toda parte, garante que vejamos as coisas longe de nós, devolver sua densidade e sua espessura àquilo que costumamos experimentar como transparência [...]. Igualmente, chegar a circunscrever, a desenhar, a designar essa espécie de ponto cego a partir do qual falamos e vemos, a reconhecer aquilo que possibilita que tenhamos um olhar distanciado, a definir a proximidade que, à nossa volta, por toda parte, orienta o campo geral de nosso olhar e de nosso saber. Apreender essa invisibilidade, esse invisível do visível demais, esse afastamento daquilo que está próximo demais, essa familiaridade desconhecida [...]. (FOUCAULT, 2016, p. 71-72, grifos nossos). 
E é neste ponto que a História, mais especificamente a História da Matemática, mostra-se como potente ferramenta de investigação e compreensão, a qual vem possibilitando entradas em emaranhados discursivos que permeiam práticas discursivas de disciplinas de Análise e adjacências. No entanto, enfatizamos que, aqui, operaremos uma história (com letra minúscula), a qual parte do pressuposto de que há uma natureza lacunar da história (VEYNE, 1982), de maneira que o presente sempre pode modificar o passado (FOUCAULT, 2015): a partir do momento em que assumimos que não há uma evolução linear, de trás para frente, da irracionalidade para a racionalidade, totalmente cronológica vetorial unidirecional da história, o que ocorre é que, na medida em que o presente se modifica, passamos a obter uma multiplicidade de passados, várias formas de redes de determinações para uma única e mesma ciência. Em outras palavras, "as descrições históricas se ordenam necessariamente pela atualidade do saber, se multiplicam com suas transformações e não deixam, por sua vez, romper com elas próprias” (FOUCAULT, 2015, p. 5, grifos nossos).

Desta forma, deixamos claro que utilizaremos a História da Matemática para compor uma história, tendo o seguinte pensamento como pressuposto:

Um acontecimento só tem sentido dentro de uma série, o número de séries é indefinido, elas não se ordenam hierarquicamente e veremos que também não convergem para um geometral de todas as perspectivas. A ideia de história é um limite inacessível, ou, antes, uma ideia transcendental. Não se pode escrever essa História, as historiografias que se acreditam totais sem se darem conta, enganam o leitor sobre sua mercadoria e as filosofias da história são um nonsense que resulta da ilusão dogmática, ou melhor, seriam um nonsense se não fossem, quase sempre, filosofias de uma "história de..." [...] (VEYNE, 1982 , p. 24, grifos do autor).

Para tentarmos dar clareza à ideia de um acontecimento dentro de uma série, tomemos um exemplo de Deleuze (2013, p. 22-23), quando este explica acerca do que Foucault entende por enunciado:

[...] é característica do enunciado poder ser repetido. Uma frase pode ser começada ou reevocada, uma proposição pode ser reatualizada, só "o enunciado tem a particularidade de poder ser repetido". No entanto, aparentemente as condições reais da repetição são bastante estritas. É preciso que haja o mesmo espaço de distribuição, a mesma repartição de singularidades, a mesma ordem de locais e de posições, a mesma relação com um meio instituído: tudo isso forma para o enunciado uma "materialidade" que o faz repetível. "As espécies evoluem" não é o mesmo enunciado quando formulado na história natural do século XVIII e na biologia do século XIX. E mesmo de Darwin a Simpson não é certo que o enunciado permaneça o mesmo, pois a descrição poderá enfatizar as unidades de medida, de distância de distribuição, e até instituições, completamente diferentes. [...] É que um enunciado se ISSN 2526-2882 
define sempre através de uma relação específica com uma outra coisa de mesmo nível que ele, isto é, uma outra coisa que concerne a ele próprio (e não a seu sentido ou seus elementos). Esta "outra coisa" pode ser um enunciado, caso em que o enunciado se repete abertamente. Mas, no limite, ele é necessariamente outra coisa que não um enunciado: é um "Lado de fora". É a pura emissão de singularidades como pontos de indeterminação, pois elas ainda não estão determinadas e especificadas pela curva do enunciado que as une e que assume esta ou aquela forma de proximidade ${ }^{133}$ (grifos do autor).

Deste modo, enunciados comuns no solo discursivo de disciplinas de Análise, tais como "A Análise é difícil”; "A Análise é formal por tradição”; "A Análise estabelece relações com a Educação Básica”, "Somente um aluno consegue ver essas relações” (GOMES, 2013), e muitos outros, parecem repetir-se há algum tempo no interior das fronteiras do discurso de disciplinas de Análise em licenciaturas em matemática. No entanto, como salienta Deleuze (compondo junto a Foucault), para que um enunciado seja efetivamente repetido, reatualizado, como diz o pensador, é necessário que ocorra toda uma gama de condições extremamente específicas - o que torna sua efetiva repetição praticamente impossível. Assim, na maioria das vezes, o que ocorre é que um enunciado torna-se totalmente diferente quando tomado novamente - já que, quando torna a ser proferido, há toda uma série diferente de acontecimentos, toda uma relação com outras coisas que difere daquelas estabelecidas no momento em que o enunciado foi proferido pela última vez. Ou seja, o que se tem é outro enunciado.

Neste diapasão, vemos que, para Foucault (2015, p.104-105), enunciado "não é uma unidade do mesmo gênero da frase, proposição ou ato da linguagem: não se apoia nos mesmos critérios; [...]. Mais que um elemento entre outros, mais que um recorte demarcável em um certo nível de análise, trata-se de uma função [...]” (grifo nosso). Uma função de existência que pertence, de maneira exclusiva, "aos signos, e a partir da qual se pode decidir, em seguida, pela análise ou pela intuição, se eles fazem sentido ou não, segundo que regra se sucedem ou se justapõem, de que são signos, e que espécie de ato se encontra realizado por sua formulação (oral ou escrita)" (FOUCAULT, 2015, p. 105, grifos nossos).

Reafirmamos, então, o quão complexo torna-se o ato de tentar compreender acerca do funcionamento de uma rede discursiva, em que os enunciados podem ser tomados como

133 Deleuze vai continuar com um exemplo: pensemos nas teclas de uma máquina de escrever (ou de um teclado de computador), Q, W, E, R e T (nos teclados franceses, A, Z, E, R e T). QWERT já é um enunciado, mas não o é cravado nas teclas - só é enunciado na medida em que se relaciona com um manual de datilografia ou de digitação, na medida em que estabelece vínculo com esse "lado de fora" do teclado e fica claro sob qual ordem tais tipos aparecem nos teclados, a partir do momento em que se define essa relação, essa função com algo a mais que os próprios tipos que fazem aparecer aos olhos o enunciado. Ainda segundo o pensador, é possível pressentir que QWERT, no teclado, "é um conjunto de focos de poder; um conjunto de relações de força entre as letras do alfabeto na língua francesa [portuguesa] segundo suas frequências, e os dedos da mão, segundo suas aberturas” (DELEUZE, 2013, p. 23-24). ISSN 2526-2882

$$
\text { * } 382
$$


elementos constituintes principais: sendo funções (funções enunciativas, como abordado por Foucault), os enunciados constituem-se, eles mesmos, como relação a uma gama enorme de outros objetos, se assim podemos dizer, de forma que tentar compreendê-los depende de toda uma busca por suas próprias regras de formação e atos de formulação e disseminação em discursos: o enunciado "não é em si mesmo uma unidade, mas sim uma função que cruza um domínio de estruturas e de unidades possíveis e que faz com que apareçam, com conteúdos concretos, no tempo e no espaço" (FOUCAULT, 2015, p. 105). Em outras palavras, um enunciado habita um entre e é pela busca por este entre, por essa função, que lançamos nossos esforços, tomando "Análise" como enunciado a ser perseguido.

\section{O que pode uma Disciplina de Análise?}

Por mais que pareça uma pergunta formulada de maneira equivocada (como dissemos, talvez fosse esperado que trouxéssemos a indagação “o que é?”), na verdade estamos tentando escapar de armadilhas discursivas que poderiam nos levar a lugares já habitados por discursos outros, viciados, talvez, numa estrutura de linearidade. Salientamos que não queremos operar aqui uma redução compreensiva, mas, sim, escapar o máximo possível de identidades discursivas e tentar compor outras coisas: descrições. Não estamos tentando alcançar capturas de sentidos, estamos querendo mesmo o contrário: o que não faz sentido quando olhamos para uma disciplina de Análise, o que escapa, o que foge de sua transparência discursiva e pode trazer elementos para atualizarmos o que entendemos por Análise?

Aliás, responder a perguntas que começam por "o que é isto", de maneira geral, sempre tende a reduzir a resposta a alguma espécie de identidade, seja ela caracterizada por visões de vários autores ou, mesmo, uma construção pessoal que, da mesma forma, ajuda a compor algo que é somente aquilo que está lá e não pode ser nada mais que aquilo. Ou seja, ao responder à pergunta “o que é isto...?” com “isto é...”, deixa-se cristalizada a identidade daquilo que é, permitindo-se que fique escondido tudo aquilo que não pode ser. Preferimos, então, caminhar pelo outro lado, o da diferenciação das diferenças (FOUCAULT, 2016).

Quando propusemos uma reflexão histórica acerca dos rastros deixados pelo enunciado "Análise", escolhemos, como dito inicialmente, um recorte de nossa dissertação (GOMES, 2013), na qual estávamos interessados em elucidar o significado de Disciplina de Análise. A produção de significados demandou uma análise sistemática, uma procura por algo que parecia habitar o próprio termo e que precisava, a todo o custo, ser elucidado - uma espécie de essência, se assim podemos dizer. Ocorre que uma produção de significado daquele tipo, como dissemos, aprisiona aquilo que se queria compreender sob uma máscara identitária e, mesmo que construída com muito cuidado e esmero, corre o risco de ter trazido em seu escopo somente aquilo que está ali e nada mais. O que queremos, agora, é operar algo pelo 
avesso, fazer aparecer o que a identidade deixou escapar, operar um escape de significados e descrever nas linhas e entrelinhas o que for possível encontrar acerca dessas pistas encontradas. Assim, o que sugerimos é uma fuga daquilo que encontramos naquele momento (quando nos propusemos a dar um significado ao termo Disciplina de Análise), buscando por relações discursivas entre o enunciado "Análise" e objetos que com ele estabeleceram e/ou estabelecem relações.

\section{Análise como função de práticas de decomposição}

O dicionário pode operar como uma espécie de gatilho para uma procura pelo "o que pode?" a partir de um discurso o mais simples e objetivo possível do "o que é" - aquele escrito nas páginas de um livro que foi feito para procurarmos por definições de palavras que desconhecemos ou que conhecemos pouco. É um início de jornada, mas que, de maneira nenhuma, se esgota. É como Deleuze e Guattari (2011) comentam: para que seja possível operar uma invasão, é necessário que um território tenha sido estabelecido, e é o território da identidade, da definição, que tentaremos invadir e no qual buscaremos criar rupturas a partir de agora.

Assim, segundo o dicionário ${ }^{134}$, vemos que análise pode significar separação de um todo em seus elementos ou partes componentes. Na tentativa de exemplificarmos tal definição, podemos pensar em um químico que, em um determinado momento, empreende esforços para averiguar quais elementos constituem certa substância: quando desenvolve tal atividade, podemos dizer que ele está analisando tal composto. Neste sentido e, tomando emprestadas as palavras de Abbagnano (2007, p. 51), vemos que análise remete,

em geral, a descrição ou a interpretação de uma situação ou de um objeto qualquer nos termos dos elementos mais simples pertencentes à situação ou ao objeto em questão. A finalidade desse processo é resolver a situação ou o objeto nos seus elementos, de modo que um processo analítico é considerado bem-sucedido quando tal resolução é realizada (grifos do autor).

Ora, com o mesmo sentido da definição anterior, mas de uma forma um tanto elaborada, Abbagnano (2007) mostra que a finalidade de um processo analítico, ou seja, daquele que se dispõe da análise para ser efetuado, é o de "resolver a situação ou o objeto nos seus elementos". Nesta definição, duas palavras aparecem em destaque e, ao procurarmos seus significados, vemos que "resolver" remete a decompor(se) um corpo em seus elementos constituintes, enquanto o termo "elemento" é compreendido como sendo parte constituinte de

134 Grande Dicionário Houaiss da Língua Portuguesa em sua versão online, disponível em http://houaiss.uol.com.br/. Acesso em: 10 fev. 2019. 
um todo. Desta feita, quando dizemos que um processo analítico tem por finalidade resolver um objeto em seus elementos, parece ser exatamente isso que significa: decompor o objeto que se analisa nos elementos que o constituem.

Desta forma, se estivéssemos satisfeitos com essa imersão nos discursos construídos junto aos dicionários utilizados, poderíamos constatar que o enunciado “Análise” remete ao ato de poder decompor algo em seus elementos constituintes. No entanto, pensamos que nossa trajetória (in)compreensiva carece de mais algumas considerações, já que o que vivenciamos junto com uma disciplina de Análise no momento de nossa graduação e também junto com outras disciplinas de Análise em nossas pesquisas, parece remeter a outras formas de relação entre o enunciado e práticas que o permeiam. Mas, seria essa relação com o ato de analisar a mais difundida e disseminada nos discursos que circundam a disciplina? Pensamos que não e, para que possamos perseguir mais rastros discursivos, reflitamos acerca do que diz o dicionário em mais um significado para o termo: análise é parte da matemática que estuda as propriedades das funções definidas em conjuntos mais abstratos nos quais ainda é possível definir a noção de continuidade.

Ora, vejamos que, pelo menos na superfície do discurso, não há nada que relacione as propriedades das funções definidas em conjuntos mais abstratos relacionados à noção de continuidade (uma compreensão acerca do enunciado “Análise” bem próxima daquela difundida em cursos de licenciatura em matemática atualmente) a aqueles processos de análise vinculados à decomposição de algo em seus elementos fundamentais. Como ocorre, então, essa aparente relação entre isto e aquilo? Aliás, seria essa uma formação discursiva ocorrida a partir de uma regularidade que coloca o enunciado "Análise" sempre em evidência e da mesma forma? Em caso afirmativo, teríamos que encontrar pelo menos uma linha que unisse esses significados e formasse a rede discursiva que os sustenta. Porém, acabamos de ver que isso não é fácil de ocorrer. Preferimos, então, seguir mais pistas.

\section{Análise como função de práticas de Geometria: análise e síntese}

Segundo Hintikka e Remes (1974, p. 3),

Análise ( $\alpha$ `ád voıs) é um método que geômetras gregos utilizaram na procura de provas de teoremas (análise teorética) e nas construções para resolver problemas (análise problemática). ${ }^{135} \mathrm{Em}$ ambos os casos, a análise

\footnotetext{
135 "No caso da análise teorética, a etapa analítica começa por assumir como verdadeiro o teorema que deseja provar. A partir dessa pressuposição inicial, ela procura encontrar uma condição anterior, da qual o teorema possa ser derivado e, sucessivamente, outra condição anterior à primeira, até que se chegue a uma verdade já demonstrada ou a um primeiro princípio. Conquistada tal proposição (um axioma ou um teorema já conhecido), procede-se à demonstração do teorema inicial, começando pelos resultados do procedimento anterior e pela inversão de seus passos, até que se tenha cumprido o objetivo (a prova do teorema). Na análise problemática, de forma similar, começa-se por assumir o problema resolvido, isto é, sua solução como dada. A partir dessa pressuposição, procuraISSN 2526-2882
} 
aparentemente consiste em tomar o que está sendo procurado, investigar de onde isto vem, e proceder desta forma até alcançar algo já conhecido. A análise é seguida por uma síntese em que o teorema desejado ou a construção são demonstrados passo a passo de uma maneira usual, de forma a refazer as etapas da análise em ordem inversa (tradução nossa).

Nesta perspectiva, a análise é pensada como um processo - como na acepção que compomos junto aos dicionários - só que, agora, aplicado a um contexto teórico matemático de busca e validação de verdades. Além disto, vemos que ela aparece acompanhada de outro processo, a síntese, a qual "pode ser considerada como o método que vai do simples ao composto, dos elementos às suas combinações, nos objetos cuja natureza se pretende explicar" (ABBAGNANO, 2007, p. 906). Mesmo que pareçam opostos (e, atualmente, é assim que são considerados), é importante frisarmos que, para os gregos, tanto análise quanto síntese mostravam-se como métodos complementares e constituintes de um único processo: na análise, assume-se como certo aquilo que está sendo procurado e, na busca de onde esta afirmação procede, encontra-se um fato já conhecido, ou seja, um fato cuja verdade já está estabelecida. Por outro lado, na síntese, assume-se o que foi obtido ao final do processo analítico e, ao prosseguir-se uma ordem natural, alcança-se o que era procurado (CORRÊA, 2008, p. 10).

Segundo Boyer (1974), há indícios de que Platão (427-347 a.C.) tenha utilizado o método analítico em seus trabalhos; no entanto, o mesmo autor diz que parece ser improvável que este pensador tenha sido realmente o primeiro ${ }^{136}$ a perceber a eficácia da análise, visto que qualquer investigação prévia de um problema poderia equivaler a isto. Desta forma, mesmo que haja vestígios de trabalhos de matemáticos que se utilizaram do método em suas buscas, vemos que a História registrou que foi somente através dos escritos de Papus (290-350 d.C.) que encontramos a "única explicação ampla dos conceitos de análise e síntese" (HINTIKKA; REMES, 1974, p. 4). Tais escritos integram a obra Coleção que, segundo Boyer (1974, p. 125), é um trabalho de extrema importância, visto que nos fornece um registro histórico muito valioso de aspectos da matemática grega, além de conter novas descobertas e generalizações que não são encontradas em nenhuma obra anterior. A Coleção é composta por oito livros, dos quais o primeiro e a primeira parte do segundo se perderam. No entanto, é no livro VII que

se encontrar, sucessivamente, etapas anteriores que possibilitem resolver o problema inicial ou derivar a solução, até ter-se encontrado um ou mais elementos já dados ou passíveis de construção. Atingido esse estágio, será possível proceder efetivamente à resolução do problema, pela inversão de seus passos, começando-se pelas etapas finais do procedimento anterior, até chegar-se ao que foi pressuposto inicialmente" (BATTISTI, 2010, p. 585).

${ }_{136}$ Segundo alguns autores, dentre eles Hintikka e Remes (1974), o método analítico já era conhecido desde Aristóteles (287 a.C. - 212 a.C.). 
pode ser encontrada uma descrição completa do que era conhecido por método de análise, além de obras conhecidas como Tesouro da Análise ${ }^{137}$. Nas palavras (traduzidas) de Papus,

[...] análise é o caminho do que se está procurando, como se estivesse estabelecido, através de suas concomitâncias [consequências] em direção a algo que é estabelecido pela síntese. Isto quer dizer que, na análise, assumimos o que é procurado como se já tivesse sido encontrado e olhamos para aquilo de que isto segue e, em seguida, para o que vem antes, até que, regressando desta maneira, encontremos algo que já seja conhecido, ou que ocupe a posição de primeiro princípio. Chamamos este tipo de método de 'análise', significando solução para trás. Na síntese, ao contrário, assumimos o que foi obtido por último na análise como já tendo sido estabelecido e, colocando agora na ordem natural, como precedentes, o que antes seguia da assunção inicial; adequando-os uns aos outros alcançamos o fim da construção do que era procurado. Isto é o que chamamos de "síntese" (PAPUS, apud HINTIKKA E REMES, 1974, p. 8-9, tradução de CORRÊA, 2008, pp. 9-10).

Vemos, então, que o enunciado “Análise" pôde ser compreendido como um método, parte de um processo que assume algo como já encontrado e, através de regressões sucessivas, torna possível encontrar algo proveniente daquilo que foi assumido; segue-se este processo até que se encontre algo que seja conhecido ou assumido como primeiro princípio, de forma que a síntese é seu caminho inverso. Ou seja, caso alguém perguntasse a Papus o que compreendia pelo enunciado "Análise", certamente a resposta seria algo relacionado a este método de descoberta e demonstração de soluções e verdades, algo como um método em que se assume algo como encontrado e, através de procedimentos sucessivos e regressivos, encontra-se quais elementos conhecidos constituem aquilo que se assumiu. No entanto, mesmo que tal definição esteja devidamente clara e estruturada dentro da série discursiva evidenciada, isto ocorre atrelado às formações discursivas que são descritas a partir das irrupções históricas daquela época, o que parece não estar relacionado - pelo menos, não em um primeiro momento, com aquilo que compreendemos por "Análise" em cursos contemporâneos de licenciatura em matemática.

Deste modo, prestemos atenção em mais um significado presente no mesmo dicionário utilizado até agora: análise é parte da matemática que estuda as propriedades das funções definidas em conjuntos mais abstratos nos quais ainda é possível definir a noção de continuidade.

Ora, tal definição difere daquela sobre a qual vínhamos refletindo até o momento, pois, ao invés de identificar análise como um método, define-a como "parte da matemática”, na qual são estudadas as funções e onde é possível definir a noção de continuidade. Desta

137 Segundo Eves (2011, p. 210), o Tesouro da Análise é uma coleção que, à maneira dos Elementos de Euclides, pretendia abarcar o material que se considerava essencial como bagagem de um matemático. ISSN 2526-2882

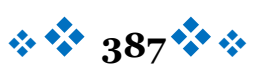


maneira, é necessário que continuemos nossas buscas por rastros discursivos que possam abarcar, também, mais esta visão acerca do enunciado.

\title{
Análise como função de práticas algébricas
}

\author{
Segundo Enros (1981, p. 136), vemos que
}

\begin{abstract}
"Analítico" significou um estilo particular de matemática. Tornou-se moda na matemática do Continente na segunda metade do século XVIII em grande parte através dos trabalhos de L. Euler (1707-1983) e J.L. Lagrange (17361813). Sua principal característica era a manipulação formal de equações, ou expressões; Analítico implicava em uma abordagem operacional algébrica ou formal para um assunto. $\mathrm{O}$ estilo alternativo era o sintético. Este englobava tudo o que não fosse algébrico. Durante a última metade do século XVIII sintético passou a incluir tudo aquilo que não era estritamente analítico (tradução nossa).
\end{abstract}

Desta forma, aquilo que para os gregos era considerado como um "método de descoberta" (CORRÊA, 2008, p. 13) a ser complementado pelo método da síntese, a partir do final do Século XVIII, passa a ser um estilo de abordagem utilizado pelos matemáticos, que tinha como oposto a síntese, agora também entendida como estilo. Mas, como isto veio a ocorrer, ou seja, de que maneira houve esta mudança de tratamento com a análise, passando de método a estilo?

Segundo Berggren et al. (2011), o Século XVII foi um período de grandes avanços na ciência, em que grandes nomes como os de Galileu (1564-1643), Descartes (1596-1650) e Isaac Newton (1642-1727) foram fundamentais para o desenvolvimento de brilhantes trabalhos, os quais podem ser considerados como verdadeiras rupturas do solo epistemológico de suas épocas.

Após a supressão da matemática grega e do período atravessado por toda a Europa denominado Idade Média, é possível observar a ocorrência de intensas atividades inovadoras no campo matemático. Dentre elas, citamos os consideráveis avanços no Cálculo Numérico, o desenvolvimento da Álgebra Simbólica, da Geometria Analítica e a ampla divulgação dos métodos do Cálculo Diferencial e Integral. É neste contexto, ao final do século XVII, que

[...] um programa de investigação baseado na análise veio a substituir a geometria grega clássica do centro da matemática avançada. No próximo século este programa continuaria a se desenvolver vinculado à física, mais particularmente à mecânica e à astronomia teórica. $\mathrm{O}$ uso extensivo dos métodos analíticos [...] e a adoção de uma atitude paradigmática com relação ao rigor lógico distinguiram a nova matemática da geometria tradicional (BERGGREN et al., 2011, tradução nossa).

Pode-se dizer que os principais responsáveis por essa renovação no modo de se fazer matemática foram Viète (1540-1603), Descartes e Fermat (1601?-1665). Ao voltarem suas 
atenções aos trabalhos de matemáticos gregos, dentre eles Apolônio (c. 262-c. 190 a.C.) e Papus, aqueles matemáticos deram uma aparência diferente ao método analítico utilizado pelos helênicos, valendo-se dele para justificar sua álgebra, a qual, advinda dos trabalhos dos árabes, ainda não tinha, perante a comunidade matemática da época, a mesma força, solidez e respeito alcançados pela Geometria clássica.

Nos trabalhos de Viète é possível observar o início desta "transformação" no tratamento da análise. Segundo Berggrenn et al. (2011), Viète, no movimento de redescoberta do método utilizado pelos gregos, propôs novos procedimentos algébricos nos quais eram empregados os conceitos de variáveis, constantes e equações, vendo isto como um avanço sobre o método analítico antigo. Segundo os mesmos autores, Viète chegou a essas conclusões ao comparar o método analítico geométrico contido no livro VII da Coleção de Papus com a análise aritmética presente na obra Aritmética de Diofanto (200c. - 284c.). Como vimos, Papus empregou o método analítico na descoberta de teoremas e na construção de soluções de problemas, admitindo como verdadeiro aquilo que era solicitado e, num movimento oposto à síntese, encontrando algo já conhecido. O que Viète fez foi abordar um problema algébrico desta mesma forma, ou seja, fundamentando o processo de encontrar o que era desconhecido em uma equação envolvendo magnitudes conhecidas em um método analítico (BERGGREN et al., 2011).

Após a morte de Viète, Descartes prossegue na utilização dessas técnicas e é visto como "um legítimo praticante do método de análise e, como tal, filia-se a essa tradição metodológica" (BATTISTI, 2002 apud BATTISTI, 2010, p. 572). No entanto, segundo o mesmo autor, vale ressaltar que há grande diferença e distanciamento entre a matemática elaborada na época de Descartes e aquela da época helênica, de modo que o método analítico dos gregos dificilmente poderia ser empregado na álgebra nascente sem que fossem feitas modificações ou adaptações. Sendo assim, "os matemáticos do início da modernidade, ao pretenderem recuperar o método dos antigos, tiveram de adaptá-lo aos 'novos tempos'. Sob esse aspecto, o enunciado "Análise" que aparece em A Geometria138 já não poderia, rigorosamente falando, ser a mesma da dos gregos" (BATTISTI, 2010, p. 572)

Posto isso, vemos que esse desenvolvimento ajudou a compor o que hoje conhecemos por Geometria Analítica, a qual parece ter suas origens nas tentativas de solucionar problemas algébrico-geométricos utilizando essa "nova análise"; vemos, também, que é através dos trabalhos de Newton e Leibniz que, como continuação e aprofundamento - não necessariamente diretos - desses estudos, fica cravado nos livros de História o nascimento do Cálculo Diferencial e Integral.

${ }^{138}$ Um dos apêndices de uma das obras mais conhecida de Descartes, O Discurso do Método. ISSN 2526-2882 


\section{Análise como função de práticas metodológicas do Cálculo Diferencial e Integral}

Segundo Berggren et al. (2011), o Século XVII pode ser compreendido como o "século da análise", em que se presenciou a consolidação do Cálculo e sua total aplicação na Mecânica. No entanto, os processos fundamentados nos indivisíveis - apesar de serem cada vez mais utilizados por se mostrarem como fortíssimas ferramentas que, de fato, funcionavam começavam a causar desconforto em certa parcela da comunidade matemática, pois muitos dos métodos utilizados pautavam-se unicamente na intuição e, dada a concepção de rigor da época, começaram a ser considerados obscuros e carentes de elucidação. Um dos matemáticos que integrou o grupo daqueles que questionaram as bases do Cálculo e, talvez, o que mais se destacou na posição de crítico dos trabalhos de Newton e Leibniz foi George Berkeley (16851753), cuja obra $O$ Analista se mostra como uma crítica brilhante e devastadora ao método infinitesimal utilizado por Newton e Leibniz (DAVIS; HERSH 1986, p. 277).

Grosso modo, Berkeley questionava a validade de se considerar uma parcela tão pequena quanto se queira, de maneira que fosse possível desconsiderá-la em determinado momento do processo analítico. Segundo Davis e Hersh (1986, p. 278), "Berkeley declarou que o processo de Leibniz, de simplesmente 'considerar 19,6 + 9,8dt como sendo 'igual' a 19,6 era ininteligível. [...] [Segundo ele,] se algo é desprezado, não importa quão pequeno, não podemos mais afirmar que temos a velocidade exata, mas somente uma aproximação".

Da mesma forma, Berkeley critica os trabalhos de Newton, dizendo:

O que são essas estas fluxões? As velocidades de incrementos evanescentes. E o que são estes próprios incrementos evanescentes? Não são nem quantidades finitas, nem quantidades infinitamente pequenas, nem mesmo nada. Não podemos chamá-los de fantasmas de quantidades desaparecidas? (BERKELEY, apud DAVID; HERSH, 1986, pp. 278-79).

Acontece que, por mais que as técnicas da "nova análise" desencadeadas por Viète e Descartes funcionassem nos problemas do Cálculo, estas ainda estavam predominantemente relacionadas a métodos geométricos e, como dissemos, havia uma tendência em considerar analítico apenas aquilo em que fosse possível empregar uma abordagem operacional algébrica ou formal (ENROS, 1981). Desta maneira, da mesma forma que a ênfase sobre a ideia de curva geométrica como objeto de estudo tinha fornecido certa coerência ao que era tido como um conjunto de diferentes técnicas analíticas (com base na Geometria), vemos que o Cálculo, com seu desenvolvimento contínuo, tornou-se gradativamente e cada vez mais distante de suas origens na geometria das curvas, de maneira que surge um movimento de forma a estabelecêlo sobre bases puramente analíticas (no sentido algébrico do termo) (BERGGREN et al., 2011).

Neste caminho, segundo Berggren et al. (2011), Leonard Euler, em uma série de livros publicados na metade do Século XVIII, realizou a separação sistemática entre o Cálculo e a 
Geometria e uma de suas mais preciosas contribuições foi ter colocado a noção de função como central no conceito da análise, definindo-a da seguinte maneira em seu Introductio in analysin infinitorum, publicado em 1748: "Uma função de uma quantidade variável é uma expressão analítica composta de qualquer modo que seja por tal quantidade variável e por números ou quantidades constantes" (BOTAZZINNI, 1986, p. 9, grifo nosso, tradução nossa). Segundo o mesmo autor, para Euler, o termo "expressão analítica" significava uma expressão composta de magnitudes simbólicas e números que se relacionam por meio de operações algébricas (adição, subtração, multiplicação, divisão, potenciação e radiciação) ou por operações transcendentais, dentre elas a exponencial, o logaritmo "e inúmeras outras que o cálculo integral fornece em abundância” (EULER, apud BOTAZZINNI, 1986, p. 9, tradução nossa).

Ocorre que a abordagem analítica de Euler deu suporte para que seu jovem contemporâneo, Joseph-Louis Lagrange, continuasse suas investigações acerca dos fundamentos do Cálculo, e vemos que

Lecionar na Ecole polytechinique levou Lagrange a refletir novamente sobre os fundamentos do cálculo, e a necessidade de fornecer um livro-texto a seus alunos estimulou-o a publicar suas aulas como a Théorie des fonctions analytiques em 1797. Neste trabalho Lagrange retomou as considerações feitas brevemente em um trabalho anterior (1772) acerca da capacidade de apresentar os princípios do cálculo de uma maneira sistemática e sem fazer qualquer referência aos infinitesimais, quantidades evanescentes, diferenciais ou limites. Ao invés disso, enfatizou a necessidade de reduzir o cálculo a simples manipulações algébricas de quantidades finitas (BOTAZZINNI, 1986, p. 48, grifos do autor, tradução nossa).

Desta maneira, é certo, então, que as críticas de Berkeley começavam a surtir efeito, pois através dos métodos analíticos propostos por Euler e seguidos por Lagrange, as bases do Cálculo começavam a ser totalmente reformuladas. Entretanto, é importante observar que o enunciado "Análise”, que neste período relacionava-se aos processos algébricos empregados pelos matemáticos "novos", pouco a pouco passou a referir-se unicamente aos assuntos relacionados ao Cálculo. Nas palavras de Berggren et al. (2011),

[...] desde Viète, a análise se referia geralmente a métodos matemáticos que empregavam equações, variáveis e constantes. Com o extensivo desenvolvimento do cálculo por Leibniz e sua escola, a análise passar a ser identificada como todos aqueles assuntos relacionados ao cálculo. Além desta associação histórica, houve um sentido mais profundo de que os métodos analíticos eram fundamentais para a nova matemática. Uma equação analítica implicava a existência de uma relação que permanecia válida com as variáveis modificadas continuamente em sua magnitude. Algoritmos e transformações analíticas implicavam uma correspondência entre uma mudança local e global, ou seja, o conceito básico do cálculo. Este é o aspecto da análise que fascinou Euler e Lagrange e fizeram-nos ver nele a "verdade metafísica" do cálculo (tradução nossa, grifos nossos). 
Vejamos que, além desta mudança dos objetos que se relacionavam com o enunciado "Análise”, os métodos analíticos passaram a fazer parte dos fundamentos da matemática que estava sendo desenvolvida, os quais eram considerados imprescindíveis no tratamento de suas estruturas. Entretanto, por mais que essas bases estivessem se tornando sólidas para aqueles que assim desejavam, havia ainda um obstáculo, talvez o maior deles, que deixava os matemáticos intrigados. Este obstáculo se tornou maior na medida em que disciplinas que compreendiam esta "nova análise" começaram a ser ensinadas e os alunos começaram a questionar seus mestres acerca de certos procedimentos - dentre eles, aquele que hoje conhecemos por limite.

\section{Análise como função de práticas limitantes infinitas}

Desde Arquimedes (287 a.C. - 212 a.C.), tratar as ideias relacionadas ao infinito sempre foi algo de difícil compreensão e aceitação no meio denominado matemático e, mesmo com tantos esforços para fazer com que o Cálculo Diferencial e Integral fosse enraizado em bases puramente algébricas, as ideias infinitesimais ainda levavam a várias conclusões que eram consideradas contradições. Desta maneira, sabe-se que no início do século XIX aconteceu um movimento com o intuito de definir o que, de fato, entendia-se por limite, o que culminou no embasamento dos fundamentos do Cálculo em conceitos puramente aritméticos. A este movimento deu-se o nome de aritmetização da Análise.

Um dos responsáveis por tal movimento - ou, pelo menos, aquele que contribuiu de maneira ímpar para que ele tivesse início - foi Augustin-Louis Cauchy (1789-1857), que, com sua obra Cours d'analyse deu nova forma ao que se entendia por rigor analítico. Em sua introdução, Cauchy diz:

Quanto aos métodos, tenho dado a eles todo o rigor que se exige na geometria, de forma a nunca raciocinar por intermédio de esboços advindos da generalidade da álgebra. Raciocinando desta forma, ao invés daquela comumente admitida, particularmente quanto a quantidades para expressões imaginárias, podem, assim me parece, somente ocasionalmente serem consideradas como conclusões convenientes para apresentar a verdade, pois estas concordam tão pouco com a precisão tão estimada pelas ciências matemáticas (CAUCHY, 1821, apud BOTAZZINI, 1986, p. 102, tradução nossa).

Nesse trecho, vemos claramente Cauchy referir-se ao seu método analítico como sendo aquele que tenta afastar-se ao máximo da "generalidade algébrica". Neste sentido, mais 
uma vez o tratamento com a análise sofre uma "transformação" 139 e vemos que todos aqueles esforços para desvencilhá-la de todo e qualquer apelo geométrico, adotando a álgebra como porto seguro para os fundamentos do Cálculo, convertem-se no empenho de negar todo fundamento algébrico e adotar a aritmética como nova sustentação, mas sempre com a visão de rigor geométrico, como uma retomada de ponto de vista. Este movimento foi denominado, como dissemos alhures, de aritmetização da Análise.

Resumidamente, podemos dizer que Cauchy contribuiu com as ideias fundamentais que vieram a dar respostas julgadas satisfatórias ou, quase, aos questionamentos propostos por Berkeley. Trata-se dos conceitos de limite e de continuidade. Vimos que até a época de Cauchy, os conceitos relacionados ao que hoje entendemos por limites estabeleciam estreita relação com a Geometria, mas, após os seus esforços, foi possível apresentá-los de forma puramente aritmética. Segundo ele,

Quando os valores atribuídos sucessivamente a uma mesma variável se aproximam indefinidamente de um valor fixado, de tal forma que a diferença entre eles seja tão pequena quanto desejarmos, este valor é chamado de limite de todos os outros. (CAUCHY, 1821 apud BOTAZZINI, 1986, p. 103, grifo do autor, tradução nossa).

Sobre continuidade, diz ele que

[...] uma função de uma variável é contínua entre os limites dados quando, entre estes limites, todo valor da variável produz um único e finito valor da função, e esta varia por graus insensíveis com a variável ela mesma. Tendo dito isto, uma função que não se torna contínua só cessará, em geral, quando se torna múltipla (CAUCHY, 1821 apud BOTAZZINI, 1986, p. 107, tradução nossa).

Esses dois conceitos mostraram-se fundamentais ao raciocínio analítico de então. No entanto, segundo Reis (2001), a maior contribuição de Cauchy para a tentativa de tornar sólidas as bases dos conhecimentos advindos do Cálculo (evidentemente, dentro do que se julgava solidez naquele momento) talvez não tenha sido a definição rigorosa e aritmética para o conceito de limite - que culminou nas definições conhecidas hoje por continuidade, diferenciabilidade e integral -, mas, sim, a maneira com que Cauchy tratou a ideia de infinitésimo. Ainda segundo ele, "a diferença fundamental em relação a muitos matemáticos anteriores é que estes concebiam o infinitésimo enquanto número fixo, ao passo que Cauchy definiu-o como uma variável independente” (REIS, 2001, p. 59). Segundo Cauchy (apud

139 Não é nosso objetivo adentrarmos na discussão dos motivos que levaram Cauchy a chegar a tais conclusões. Para os que se interessarem no aprofundamento no assunto, sugerimos fortemente a leitura de Botazzini (1986) e Vianna (2009).

ISSN 2526-2882 
BOYER, 1974, p.380), "diz-se que uma quantidade variável se torna infinitamente pequena quando seu valor numérico decresce indefinidamente de modo a convergir para o limite zero".

Sendo assim, vemos que Cauchy baseou o Cálculo sobre uma interpretação ao mesmo tempo difícil e sofisticada de dois números que se tornam arbitrariamente próximos, o que gradativamente estabeleceu e refinou a maneira como o cálculo rigoroso passou a ser visto. Este "novo cálculo" passou a ser encarado como um objeto totalmente original, e que passou a ser denominado por “análise matemática” (BERGGREN et al., 2011). Desta forma, é certo que os trabalhos de Cauchy foram de suma importância para que este novo campo fosse concebido e estabelecido. Nas palavras de Botazzini (1986, p. 102), “O Cours d'analyse tornou-se o manifesto da "nova análise”, um livro que, como Abel escreveu, 'deve ser lido por todo analista que deseja rigor em investigações matemáticas”" (tradução nossa).

\title{
Análise como função de práticas estruturantes de um corpo ordenado completo
}

Sabe-se que os trabalhos de Cauchy logo se mostraram incompletos, pois, por mais que estivessem de acordo com o rigor exigido na época, fundamentavam-se em uma ideia completamente intuitiva do sistema de número real (REIS, 2001). Não é necessário ser um matemático profissional para saber que a intuição não é bem vista quando o assunto é estruturar uma teoria, creio que muitos dos que estão lendo passaram por isso em seus cursos de graduação. Desta forma, faltava ainda mais um passo em direção a uma considerada completa solidificação das bases do que se denominava, e ainda se entende, por análise. Segundo aquele mesmo autor,

\begin{abstract}
Tendo, pois, como principal motivação a Análise deixada por Cauchy, Weierstrass $(1815$ - 1897) defendeu a necessidade de que o sistema de números reais fosse tornado rigoroso, o que se concretizou, no final do século XIX, com Dedekind (1831 - 1916) e Peano (1858 - 1932), que mostraram como o sistema dos números reais pode ser deduzido de um conjunto de postulados para o sistema dos números naturais; o primeiro com sua noção de "corte", que permitiu a demonstração rigorosa dos teoremas fundamentais sobre limites sem utilizar recursos geométricos e o segundo, que introduziu um "simbolismo" uniforme, criando assim, uma nova forma de lógica matemática (REIS, 2001, p. 60)
\end{abstract}

Sem adentrarmos em discussões acerca dos trabalhos de cada um desses matemáticos, vemos que o exaustivo trabalho de colocar as ideias do Cálculo em bases consideradas firmes culminou na definição do que hoje conhecemos por número real e o estabelecimento de suas bases totalmente aritméticas abriu possibilidade para que a teoria dos conjuntos fosse concebida, de forma que as ideias analíticas pudessem ser deduzidas a partir do conjunto dos números naturais. Assim, podemos dizer que as disciplinas de Análise 
atualmente oferecidas na maioria dos cursos de licenciatura em matemática concebem o enunciado "Análise" desta forma.

\section{Algumas considerações}

Pensamos que o que propusemos no início deste pequeno artigo foi contemplado: estávamos interessados em perseguir pistas discursivas acerca do enunciado "Análise" e fizemos isso descrevendo pelo menos seis séries nas quais o enunciado estabelece relações com outros objetos: Análise como função de práticas de decomposição; Análise como função de práticas de Geometria: análise e síntese; Análise como função de práticas algébricas; Análise como função de práticas metodológicas do Cálculo Diferencial e Integral; Análise como função de práticas limitantes infinitas e Análise como função de práticas estruturantes de um corpo ordenado completo.

É interessante pensar que há outras formas de se estabelecer relação com um enunciado que, à primeira vista, parece ser tão trivial quando levamos em consideração cursos de licenciatura em matemática - a Análise é aquela disciplina em que se estudam os fundamentos do Cálculo, diriam muitos. Se pensarmos no primeiro movimento que compomos para o enunciado "Análise", ou seja, aquele que toma algo como estabelecido e, a partir de regressões sucessivas, chega a algo conhecido (ou primeiros princípios), vemos que parece se ajustar adequadamente ao que foi realizado com as bases do Cálculo e, desta maneira, tendemos a acreditar que aquele processo analítico dos gregos pode ser visto claramente no processo que estabeleceu os fundamentos do campo atualmente conhecido como Análise Matemática. No entanto, se pensássemos somente desta forma, cairíamos na armadilha da linearidade histórica (VEYNE, 1982) ou das continuidades irrefletidas (FOUCAULT, 2015).

Assim, preferimos refletir que é, no mínimo, interessante que um método forjado no contexto da geometria grega, em certo momento da história, passe a designar processos que tendem a se distanciar deste ramo e conceber somente aquilo que é algébrico. Ainda mais, com o desenvolvimento das ideias relacionadas ao rigor, aquilo que é analítico passa a negar tais processos algébricos e a considerar somente aqueles aritméticos. Como tais mudanças ocorrem, visto que parecem ser tão difusas?

Ora, aqui é necessário fazer o que sugere Foucault (2015, p.31): quando estamos em relação com um enunciado

É preciso estar pronto para acolher cada momento do discurso em sua irrupção de acontecimentos, nessa pontualidade em que aparece e nessa dispersão temporal que lhe permite ser repetido, sabido, esquecido, transformado, apagado até nos menores traços, escondido bem longe de todos os olhares, na poeira dos livros. Não é preciso remeter o discurso à longínqua 
presença de sua origem; é preciso tratá-lo no jogo de sua instância (grifo nosso).

Esse jogo discursivo, se assim podemos dizer, tem suas próprias regras de funcionamento e é a partir da tentativa de se compreender essas regras que podemos afirmar que houve diversas "Análises", uma para cada jogo discursivo estabelecido e forjado a partir da atualização do saber relacionado àquele jogo e àquelas regras: quando ideias novas são estabelecidas, a virtualidade daquele enunciado é atualizada e novas relações são estabelecidas. Em outras palavras, a partir do momento em que a História estabelece alguma função entre enunciado e outras coisas que a ele se relacionam, passa a existir outro enunciado, outra história.

No entanto, algo vem nos chamando atenção e é sobre isso que nos debruçamos, atualmente, em nossa pesquisa de doutorado: se partirmos do pressuposto de que "as verdades são ilusões, das quais se esqueceu o que são, metáforas que se tornaram gastas e sem força sensível, moedas que perderam a sua efígie e agora só entram em consideração como metal, não mais como moedas" (NIETZSCHE, 1999, p. 57) e alinhavarmos essa ideia ao pensamento de Foucault (2015) acerca da produção e disseminação (bem como deflagração e desaparecimento) de discursos - o qual demonstra que há toda uma rede discursiva, ou melhor, de práticas discursivas, em que se emaranham os discursos tomados como verdadeiros e vindouros, e também os ditos falsos e esquecidos - somos levados a constatar que as maneiras utilizadas para se verificar uma verdade necessitam, elas mesmas, serem constatadas como verdadeiras.

Ou seja, o critério para se verificar a veracidade de algo deve ser verdadeiro e essa veracidade do critério deve (?) ser atestada por algo ou alguém, de modo que seu discurso seja, ele mesmo, crível e entendido como verdadeiro. Quem ou o que faz isso? É algo posto por alguma entidade ou algum sentimento, nato a todo e qualquer ser humano, percebido sempre como algo a priori de toda verdade? Seria uma força verdadeira que habita cada um de nós, essência do ser humano, bem supremo alcançável somente com muito esforço e pelas mais brilhantes mentes da humanidade? Acreditamos que não, e o que expomos leva a essa conjectura: são construções discursivas, cujas regras de formação, permanência e deflagração necessitam ser compreendidas, para que, somente após isso, seja possível conferir algum grau de significado ou mesmo uma qualidade de verdadeiro ou de falso. Ademais, ainda não temos condições de seguir adiante neste tipo de reflexão, seja devido aos limites deste artigo ou mesmo aos limites de nossa própria pesquisa de doutorado, ainda em desenvolvimento.

Quando nos deparamos com situações em que alunos de licenciatura em matemática ou mesmo professores da educação básica se veem de frente a questionamentos como os elencados pelos dois sujeitos apresentados no início deste artigo, dificilmente pensamos que ISSN 2526-2882 
cada uma delas, ou mesmo a mesma pessoa, pode ter ideias diferentes acerca do que signifique aquela disciplina de Análise com a qual estabelece relações. Um estudante que está cursando pode ter várias visões (ou uma, ou nenhuma) acerca de toda a problematização inerente à consolidação de um campo do conhecimento e sua institucionalização como disciplina em um curso de nível superior - e essas visões (ou não-visões) geralmente são carregadas para a sala de aula em que atuará, de forma que é grande a probabilidade de ele tentar reproduzir os mesmos discursos disseminados e interiorizados.

Ao propormos a pergunta "o que pode", pensamos, como dissemos, em contribuir para que essa máquina denominada Análise tenha as suas engrenagens colocadas em total evidência, de maneira a tornar possível, para aquele que pergunta, poder estudá-las, uma a uma, e tomar suas próprias decisões acerca de a qual linha dar mais ênfase no momento em que está em relação com a Análise, seja na posição de aluno, seja na posição de professor ou pesquisador. A potência advém dessa estrutura densa invisível que fica, em um primeiro momento, submersa numa transparência discursiva, em que todos escutam e continuam reproduzindo aquilo que escutaram, porque creem piamente que aquilo que está sendo proferido com tanta propriedade só pode ter sido estruturado daquela forma e de nenhuma outra: não haveria de existir outra possibilidade para aquilo que é tão formal e rigoroso dentro dos limites de um curso de licenciatura em matemática, por exemplo. Acreditamos que conseguimos mostrar exatamente o contrário: ao perseguir rastros discursivos acerca do enunciado "Análise”, podemos trazer mais densidade a essa transparência, e as possibilidades de compreensão tendem a aumentar na medida em que se mergulha nessa névoa.

Quando isso não é feito e a transparência insiste em permanecer, o que acaba restando aos sujeitos que com o enunciado "Análise” estabelecem relação é uma espécie de aceitação, como podemos observar na fala de uma professora da educação básica entrevistada em nossa pesquisa de mestrado:

Pra que Cálculo se eu não vou trabalhar isso no ensino fundamental?”, a gente questionava... Mas em Análise eu não sei se a gente chegou ao ponto de desistir e não questionar ou se era por conta também do professor que da/... Mas eu acho que não, eu acho que a gente já não estava mais questionando nessa fase, já estávamos no último sem/... praticamente no penúltimo semestre do curso, a gente não fazia mais esse tipo de questionamento. (GOMES, 2013, p. 188, grifos nossos).

Pensamos que essa desistência vem exatamente da perda de significado que a disciplina passa a ter para o aluno, de forma que resta a ele se esforçar para obter a aprovação. No entanto, o que ocorreria se esse sujeito adentrasse em todo o emaranhado discursivo, o qual este artigo começou a explicitar, e pudesse ir ao encontro de toda a multiplicidade com a qual o enunciado "Análise” manteve relação? O que poderia ocorrer se, em cursos de licenciatura ISSN 2526-2882 
em matemática, toda essa metamorfose histórico-discursiva fosse apresentada aos alunos, de forma a deixar por conta deles a formação de suas próprias compreensões acerca do que sustenta os discursos em que estão inseridos?

São perguntas que nos interessam, mas que, por hora, serão deixadas em suspenso. O que gostaríamos de fazer foi feito: há vários rastros discursivos para que o leitor possa seguir aquele(s) que considerar mais interessante(s) e possa, ele mesmo, construir sua própria rede compreensiva na tentativa de oferecer uma(s) resposta(s) ao questionamento: o que pode uma disciplina de Análise?

\section{Referências}

ABBAGNANO, N. Dicionário de Filosofia. 5. ed. São Paulo: Martins Fontes, 2007.

BATTISTI, C. A. O método de análise cartesiano e o seu fundamento. In: Scientiæ Studia: Revista Latino-americana de Filosofia e História da Ciência, São Paulo, v. 8, n. 4, p. 571-596, 2010.

BERGGREN, J. L.; FOLKERTS, M.; FRASER, C. G.; GRAY, J. J.; KNORR, W. R. Mathematics. Academic Room, 2011. Disponível em: http://www.academicroom.com/topics/mathematics-definition. Acesso em: 10 fev. 2019.

BOYER, C. B. História da Matemática. São Paulo: Edgard Blüsher, Ed. da Universidade de São Paulo, 1974.

BOTTAZZINI, U. The Higher Calculus: A history of Real and Complex Analysis from Euler to Weierstrass. New York: Springer-Verlag, 1986.

CORRÊA, B. M. A Introdução à Arte Analítica de François Viète: comentários e tradução. 2008. 141 f. Dissertação (Mestrado) - Universidade Federal do Rio de Janeiro, Rio de Janeiro, 2008.

DAVIS, P. J.; HERSH, R. A Experiência Matemática. Rio de Janeiro: Francisco Alves, 1986.

DELEUZE, G.; GUATTARI, F. Mil Platôs: capitalismo e esquizofrenia 2. Vol. 1,2,3,4, e 5 ( $2^{\text {a }}$ ed). São Paulo: Editora 34, 2011.

DELEUZE, G. Foucault. São Paulo: Brasiliense, 2013.

ENROS, P. C. Cambridge University and the adoption of analytic in early nineteenthcentury England. In: MEHRTENS, H.; ROS, H.; SCHNEIDER, I. (Edts.). Social History of Nineteenth Century Mathematics. Boston: Birkhauuser, 1981. p. 135-148.

EVES, H. Introdução à História da Matemática. Tradução de Hygino H. Domingues. 5 ed. Campinas/SP: Editora da Unicamp, 2011.

FOUCAULT, M. O belo perigo. Belo Horizonte: Autêntica Editora, 2016. 
FOUAUlT, M. A Arqueologia do Saber. 8. ed. Rio de Janeiro: Forense Universitária, 2015. GOMES, D. O. A Disciplina de Análise segundo Licenciandos e Professores de Matemática da Educação Básica. 2013. Dissertação (mestrado). Instituto de Geociências e Ciências Exatas, Universidade Estadual Paulista, Rio Claro/ SP, 2013.

HINTIKKA, J.; REMES, U. The method of analysis: its geometrical origin and its general significance. Dordrecht: Reidel, 1974.

MARTINES, P. T. O papel da disciplina de Análise segundo professores e coordenadores. 2012. Instituto de Geociências e Ciências Exatas, Universidade Estadual Paulista, Rio Claro/ SP, 2012.

MOREIRA, P. C.; VIANNA, C. R. Por que Análise Real na Licenciatura? Um paralelo entre visões de Educadores Matemáticos e de Matemáticos. BOLEMA [online]. 2016, vol. 30, n. 55, p. 515-534.

MOREIRA, P. C.; CURY, H. N.; VIANNA, C. R. Por que Análise Real na Licenciatura? Zetetiké, Campinas, n.23, p.11-42, 2005.

NIETZSCHE, F. Sobre a verdade e a mentira no sentido extra-moral. In: Nietzsche: obras incompletas. São Paulo: Nova Cultural, 1999. p. 51-60.

OTERO-GARCIA, S. C. Uma Trajetória da Disciplina de Análise e um Estado do Conhecimento sobre seu Ensino. 2011. Dissertação (Mestrado). Instituto de Geociências e Ciências Exatas, Universidade Estadual Paulista, Rio Claro/ SP 2011, v. 1.

REIS, F. da S. A Tensão Entre Rigor e Intuição no Ensino de Cálculo e Análise: a visão de professores-pesquisadores e autores de livros didáticos. 2001. 302f. Tese (Doutorado) - FE/Unicamp, Campinas (SP), 2001.

SILVA, L. D. da. Conhecimentos presentes na disciplina de Análise nos cursos de licenciatura em Matemática no Brasil. 2015.Tese (Doutorado em Educação Matemática). Instituto de Geociências e Ciências Exatas, Universidade Estadual Paulista, Rio Claro/ SP, 2015.

SOARES, E. F.; FERREIRA, M. C. C.; MOREIRA, P. C. Números reais: concepções dos licenciandos e formação matemática na licenciatura. Zetetiké. Campinas, v. 7, n. 12, p.99-117, 1999.

VEYNE, P. M. Como se escreve a história; Foucault revoluciona a história. Brasília: Editora Universidade de Brasília, 1982.

VIANNA, R. N. G. Um estudo do Cours d'Analyse Algébrique de Cauchy em face das demandas do ensino superior científico na Échole Polytechnique. 2009. 127 f. Dissertação (Mestrado) - Universidade Federal do Rio de Janeiro, Rio de Janeiro, 2009.

ISSN 2526-2882 


\section{Biografia Resumida}

Danilo Olímpio Gomes. Graduando em Licenciatura em Matemática pelo Centro Universitário UniFafibe - Campus Bebedouro/SP (2008), mestre em Educação Matemática pela Universidade Estadual Paulista Júlio de Mesquita Filho, UNESP - Campus Rio Claro/SP (2013) e doutorando em Educação Matemática pela mesma universidade. Atualmente é professor do Ensino Básico, Técnico e Tecnológico no Instituto Federal de Educação, Ciência e Tecnologia de Alagoas - IFAL, Campus Piranhas; Membro do grupo de estudo/orientação/pesquisa CRONÓPI@S, em que discussões acerca de obras afins da Filosofia, Filosofia da Educação Matemática, Filosofias da Diferença, Etnomatemática e História da Matemática ocorrem de forma periódica junto aos departamentos de Educação/Educação Matemática da UNESP de Rio Claro/SP; Participação no grupo de pesquisa I-mago (Laboratório de Experiência e Cria[@]cão), UNESP - Rio Claro/SP

Link Lattes: http://Link Lattes.cnpq.br/7107392295236273 e-mail: danilo.o.gomes@gmail.com 